\title{
Identidades narrativas, los usos sociales de lo popular y la telenovela
}

\author{
Salvador Orlando Alfaro \\ Universidad de Regina, Canadá
}

RESUMEN: Las telenovelas cumplen funciones sociales que antes cumplian otros productos culturales, muy vinculados a prácticas sociales determinadas Sus funciones tienen un carácter marcadamente mediatizado y están apoyadas por una plataforma mediática que no ba sido democratizada y que, además, escapa a las regulaciones del Estado. Constituyen, por eso mismo, una vía importante para comprender la configuración de nuestras identidades.
ABSTRACT: Soap operas accomplish social functions that were accomplished in the past by other cultural products that were closely linked to certain social practices. Its functions have a remarked mediatized character and are supported by a media platform that has not been democratized and is free from public regulations. Thus, soap operas are, for this reason, an important source for understanding how our societies are configured.

\section{I}

En los últimos quince años se ha producido un importante cambio en la manera de abordar la problemática de las identidades sociales. Obviamente ligado a lo que se dio en llamar "el giro lingüistico" en las ciencias sociales, pero precisando mucho más la relación entre identidades y discursos, este cambio hace énfasis no sólo en el origen discursivo de las identidades (algo ya avanzado por las corrientes sociológicas interaccionistas y estructuralistas), sino también en su origen narrativo.

\section{1}


Para expresarlo en muy pocas palabras, se podría decir que esta nueva manera de estudiar las identidades sociales sostiene, parafraseando a Fredric Jameson (1981), que la narrativa es una categoría epistemológica que fue tradicionalmente confundida con la forma literaria. Y no sólo esto sino que, de acuerdo con Ricoeur (1984), la narrativa es uno de los esquemas cognoscitivos más importantes con que cuentan los seres humanos, dado que permite la comprensión del mundo que nos rodea de manera tal que las acciones humanas se entrelazan de acuerdo a su efecto en la consecución de metas y deseos. En otras palabras, si por un lado parece no haber comprensión del tiempo humano fuera de su inserción en un marco narrativo, por el otro, la narrativa sería la única forma cognoscitiva con que contamos para entender la causalidad en relación a las acciones humanas.

Siguiendo estas intuiciones analíticas, se puede argumentar que la identidad social se basa en una continua lucha discursiva acerca del sentido que define las relaciones sociales y posiciones de una sociedad y tiempo determinados. Uno de los resultados de esta lucha discursiva es que los nombres y los símbolos que definen a las diversas relaciones y posiciones sociales entran a formar parte del reino del sentido común (Gramsci 1975: 1396) impregnados con las connotaciones propuestas por los "ganadores" de esta batalla por el sentido. Esto es así porque este proceso de uni-centualidad implica una práctica "clausura”, esto es, el establecimiento de un particular sistema de equivalencias entre lenguaje y realidad (Volosinov 1973: 23). Así, la construcción social de las identidades involucra una lucha alrededor de las formas en que el sentido queda "fijado". Sin embargo, esta noción de clausura es siempre condicional en este tipo de planteamiento teórico, que los sentidos que han sido exitosamente acoplados a cierta realidad, siempre pueden ser desacoplados de la misma. De ahí que la lucha por el sentido de una identidad y posición de sujeto nunca esté completamente cerrada. En otras palabras, la identidad social y la subjetividad son siempre precarias, contradictorias y en proceso, y los individuos son siempre el espacio de lucha de conflictivas formas de subjetividad.

Por lo tanto, las diferentes posiciones de sujeto que convergen para formar lo que a primera vista aparece como un individuo "único y unificado" son en realidad construcciones culturales que reflejan condiciones sociales contradictorias y correlaciones de poder específicas. Usualmente la gente encuentra los discursos que les permite armar las identidades 
en las diferentes contrucciones culturales de una época y una sociedad determinadas. Así, es precisamente en el reino de la cultura donde se desarrolla la lucha por el sentido de las diferentes posiciones de sujeto, y los productos de la cultura de las masas son una fuente muy importante de tal tipo de discursos.

Por supuesto no todas las opciones tienen la misma fuerza en la lucha por el sentido, y aquí aparece el problema de la construcción de la hegemonía (Gramsci 1971: 161). Esto es así, dado que dicha construcción se realiza esencialmente, a través de la propuesta de identidad que se les hace a los diferentes actores sociales; propuesta de identidad o de posiciones de sujetos que son funcionales a los intereses de los grupos hegemónicos. De ahí que se pueda afirmar que la batalla hegemónica más importante se gana cuando los actores sociales aceptan (por supuesto que a través de un proceso muy complejo de reconocimiento, lucha y negociación) las posiciones de sujeto tal cual son ofrecidas por el grupo hegemónico. Y es aquí justamente donde donde convergen la función de la hegemonía con el de los productos culturales.

Tomadas en consideración estas indicaciones teóricas, en este trabajo se pretende evidenciar la importancia que tiene uno de los productos de la cultura de masas: el género mediático y su impacto en la cultura popular y en los procesos de identidad en la sociedad latinoamericana contemporánea. Casi con certeza se puede afirmar que dentro de este género la telenovela ocupa un lugar privilegiado y que por lo tanto su estudio resulta primordial y sobre todo si se le contextualiza en relación a los procesos de hegemonía y reforma social que experimenta la "sociedad del riesgo" latinoamericana. Para comenzar se podrían plantear las siguientes interrogantes: ¿cuáles son los usos sociales que el "público" le da a un género mediático como la telenovela en la actualidad? ¿Cuál es la relación que existe entre este género y los procesos de identidad contemporáneos?

En términos más específicos, el resto de la discusión se centra en despejar las siguientes preguntas: qué es en la actualidad lo popular (Williams 1983) y cómo se escenifica concretamente en las telenovelas que se trasmiten cotidianamente en la televisión salvadoreña. Se discuten en torno a ellas las relaciones conflictivas entre lo real y lo ficticio y los usos sociales dados por el público a esas escenificaciones, usos que se vinculan con la conformación de identidades, con nuevas formas de negociación, participación, recepción y significación de la hegemonía 
desde lo popular. En este recorrido la discusión se apoya en las líneas teóricas y metodológicas planteadas por Jesús Martín-Barbero (1987) y por Néstor García Canclini (1989), en dos textos que resultan muy útiles para reflexionar sobre la cultura mass-mediática, ya que enriquecen la discusión con la matriz sociológica, centrándose no sólo en los productos, sino también en los canales y redes, formas de producción, mercados, circuitos y públicos.

Al moverse más allá de las contribuciones de la Escuela de Frankfurt (Kellner 1989), se puede comprender la telenovela como el espacio cultural definido especialmente por la negociación simbólica y la entretención, en un contexto mediático, que no implica sólo desarrollo de tecnología comunicacional, sino el permanente cambio e hibridación que vive la cultura popular y los sujetos que la experimentan, ya sea desde la recepción como desde la producción. Se puede entender lo popular, siguiendo a Martín-Barbero, como el complejo entramado que ha transformado al "pueblo" en público, en un lento proceso que se inicia, conceptualmente, con la contradictoria puesta en marcha del mito del pueblo en la política por los ilustrados y en la cultura por los románticos, para luego, fundiendo política y cultura, afirmar la vigencia moderna de lo popular por el anarquismo o negarla por su "superación" en el proletariado por las corrientes marxistas occidentales.

Junto con las grandes y lentas transformaciones que conlleva, del siglo XVI al XIX, a la formación del Estado moderno y su consolidación definitva en Estado-Nación, se le va negando validez a lo popular, asimilándolo a lo vulgar, retrasado y bárbaro. La cultura nacional les niega el derecho a existir a las culturas populares. La destrucción de lo popular, la eficacia de su represión, proviene y se produce desde una multitud de mecanismos y procedimientos dispersos y a veces contradictorio. En dos planos se hace claro el sentido de la enculturación: el de la transformación del sentido del tiempo y el de las transformaciones del saber, el que se homogeniza a través fundamentalmente de la institución escolar y su papel como aparato ideológico del Estado capitalista. Será, sin embargo, en ese momento de dominación, donde lo popular manifestará sedimentos de resistencia y contrahegemonía (Martín-Barbero 1987: 108-109). 
Para García Canclini (1989), en una línea semejante, lo popular permanence siempre escenificándose y transformándose, y lo hace por lo menos a través de tres ejes de sentido: desde lo folklórico rural, dede las industrias culturales (espectáculo, popularidad) y desde el populismo.

En un proceso algo posterior, según Martín-Barbero, el melodrama, el gran espectáculo popular del siglo XVIII, sería el vértice mismo del proceso que lleva lo popular a lo masivo. "Lugar de llegada de una memoria narrativa y gestual populares y lugar de emergencia de una escena de masa, donde lo popular empieza a ser objeto de una operación de borradura de las fronteras que arranca con la construcción de un discurso homogéneo y una imagen unificada de lo popular, primera figura de la masa” (Martín-Barbero 1987: 124). Una de las operaciones constantes de esa matriz cultural será la esquematización y la popularización.

En un tercer movimiento, lo masivo o las masas se transforman en la masa, la hegemonía se ejerce ya no con la sumisión sino con el consenso. Esto se produce a través de múltiples y variados procesos, según Martín-Barbero, siendo uno de los de más largo alcance: la disolución del sistema tradicional de diferencias sociales, la constitución de las masas en clase y el surgimiento de una nueva cultura, la de la masa. El vacío abierto por la desintegración de lo público será ocupado por la integración que produce lo masivo, la cultura de la masa. Ese es el lugar donde se borrran (simbólicamente) las diferencias sociales. "Masa designa, en el movimiento del cambio, el modo como las clases populares viven de las nuevas condiciones de existencia, tanto en lo que ellas tienen de opresión como en lo que las nuevas relaciones contienen de demanda y aspiraciones de democratización social. Y de masa será la cultura que llaman popular. Pues en ese momento, en que la cultura popular tendía a convertirse en cultura de clase, será esa misma cultura minada desde dentro y transformada en cultura de masa, la que emergerá" (MartínBarbero 1987: 135).

\section{III}

En este sentido se puede entender las telenovelas como un género heredero de manifestaciones anteriores a la irrupción de los medios masivos de comunicación, pero contemporáneas a la masificación de la sociedad. "La constitución histórica de lo masivo más que a la degradación de la cultura por los medios, se halla ligada al largo proceso de gestación del mercado, el estado y las culturas nacionales, y a los dispo-

\section{5}


sitivos que en esos procesos hicieron entrar a la memoria popular con el imaginario de la masa" (Martín-Barbero 1987: 135). En este contexto, la comunicación se puede comprender como un hecho de la cultura, la mediación como la "apropiación desde los usos y sus relaciones con la vida social”, y la telenovela, como un género discursivo histórico, que debe ser pensado no desde la hegemonía, sino desde la circulación cultural, o más bien, desde una hegemonía que no anula con su dominación lo popular. O sea, no obstante la hegemonía que ejerce la industria cultural, lo popular se expresa, ya sea como representación, como público interpelado o bien como sujeto productor de otras nuevas.

Sin duda, existe una "modernidad de los receptores" (García-Canclini 1989: 129) que no ha sido estudiada en América Latina, y que influye decididamente en la configuración del espacio de los productos mass-mediáticos. Ahí donde tradicionalmente los estudios semióticos se centraron en el mensaje y su estructura, sin influir de una manera significativa en los procesos productivos de la industria de la cultura de masas, el polo de la recepción influía con su crítica y lúcida actividad en la producción real de esos mismos productos. Esto quiere decir, que géneros como la telenovela, sufren en su interior mutaciones y transformaciones determinadas por los usos sociales que el público receptor ha ido realizando sobre ella. De ahí que la preocupación por lo popular se celebre aquí en aquello que se transforma, y no tanto en lo que se extingue. Eso, porque para la producción de una telenovela se considera no sólo el genio creador del libretistas y directores, sino también sondeos de opinión, encuestas focalizadas, rating de producciones anteriores, zonas en las que los públicos, especialmente de las clases populares y medias, depositan sus aprehensiones, críticas, lecturas de lo social, experiencias (cognitivas y pragmáticas), en definitva, un saber. Un saber con relación al género mediático y un saber más general, que se resuelve no sólo en el campo de la entretención espectacular, sino en una compleja amalgama de experiencia vital, cultural, social, personal y colectiva. Los usos están determinados por el sector social al que pertenece el público y por sus respectivas competencias culturales.

Las telenovelas cumplen funciones sociales que antes cumplían otros productos culturales, muy vinculados a prácticas sociales como la fiesta, el carnaval, el circo, el teatro de plaza, el melodrama, el folletín. Las funciones que cumple hoy la telenovela son muy semejantes a la de aquellas prácticas culturales, pero de una manera mediatizada y en un medio, 
como la televisión, que en El Salvador que no ha sido democratizado ni regulado suficientemente, debido a un proceso de control y privatización apoyado especialmente por las políticas neoliberales de los últimos gobiernos de la derecha local. De ahí su pertinencia cuando se quiere comprender las maneras híbridas y desiguales en que se configuran nuestras identidades, para dejerla de entenderlas como reflejos o ethos culturales, internalizados y socializados de una vez y para siempre, sino como desafíos, como configuraciones en constante cambio, realización y tensión. A veces también como espacios entre intereses comerciales y necesidades sociales (no es irrelevante el hecho que en El Salvador y en el mundo el control de los grandes medios se concentra en muy pocas manos), entre ética y la estética, entre lo simbólico y lo real. La identidad entonces está marcada por diferencias sociales, culturales y génericas, étnicas, etc.; lo que se explica profundamente en las formas desiguales de la reapropiación que efectúan diferentes sectores en torno a un mismo producto cultural.

La telenovela es heredera de muchas manifestaciones culturales, siendo el folletín, el melodrama, el teatro de plaza y el radio teatro los que más han contribuido con sus matrices de sentido y de estructura a su configuración. Al ser emitida por entregas produce la sensación del diario vivir, del día a día, del tiempo real, de ahí las maneras que tiene de convivir con la sociedad: no sólo durante su emisión, sino también su presencia en las conversaciones cotidianas y en la contrucción de identidades, comportamientos y en los imaginarios locales y continentales.

Este género es una construcción imaginaria y mediática reciente, y uno de los pocos productos culturales originales de América Latina, aunque tiene, como ya se ha indicado, matrices culturales históricas provenientes de otras latitudes. En su estructura narrativa están causalidad, la trama intricada en el tratamiento de los personajes del melodrama, además de su tema fundamental: el triunfo de los buenos sobre los malos: del folletín está la fragmentación generadora del suspenso, la serialidad (repetición e innovación) y el provilegio por los dramas sociales: sobreviven también algunos temas de la literatura de masas: novela rosa, de aventuras, policial, etc.; la influencia del radio teatro en la circulación de libretos, autores y actores, género con el que convive hasta los años sesenta.

La telenovela responde a necesidades sociales profundas como lo son el reconocimiento social (Martín-Barbero 1987: 95), la identifica-

\section{7}


ción (con determinados personajes), la proyección (de sentimientos, de estados de ánimo) y la catarsis. Es, además, una de las industrias culturales de exportación al resto del mundo. Se instala además en el intersticio entre lo real y lo ficticio, entre lo cotidiano y lo excepcional, entre el pesado tiempo histórico real y el liviano tiempo del día a día. Frivolidad y superficialidad y estereotipos, pero también compleja creación y producción, públicos masivos, propagación de modos y éticas de comportamiento, leve forma de participación (a través del rating, de las encuestas y de las cartas), entretención y voyeurismo. Detalles no menores a la hora de sumar y restar. La telenovela desempeñaría, además, al igual que otros dispositivos ideológicos, la función de osmosis entre la corriente burguesa y el imaginario popular, al sumar a las falsas identidades la búsqueda del éxito social y los conflictos sentimentales. El amor y la educación serán el eje a través del cual se produce la única forma de redención: la movilidad social. Sueños ilustrados y románticos, pero profundamente vigentes en el imaginario popular.

Por eso, Martín-Barbero llama a poner el acento, más que en los mensajes, en las mediaciones a través de las cuales los productos de la cultura de masas se instalan en nuestro imaginario y en nuestra realidad; mediaciones que ponen en relación y tensión también las diferencias étnicas, sociales, génericas, nacionales, individuales, etc. De ahí que él mismo indique que no son los mensajes ni los medios electrónicos en sí los que cambian la cultura, sino sus usos sociales, los que operan en una relación de continuidad con la industrialización, la urbanización, la educación y los movimientos sociales. Los medios de comunicación no sólo han cambiado los "canales" de comunicación, sino la forma total de a través de la cual la sociedad participa y dialoga.

\section{IV}

En la actualidad la prensa tradicional y la industria del relato se dan la mano y confunden los límites entre lo real y lo ficticio, entre la historia y la imaginación. El sociólogo francés Edgar Morin señala, en varios de sus trabajos, que la función que cumplen los medios tradicionales ha cambiado: al brindarle éstos relativa importancia o preeminencia al mensaje o los contenidos para conventirse en mediadores, en comunicadores entre lo real y lo imaginario. Es cosa de pensar en la tendencia existente en una importante cantidad de periódicos de quererse asemejar a la industria de la entretensión: menos palabras y más imágenes, menos intelecto y más corazón. Eso explicaría los grados de confusión 
entre la ficción y la realidad que participan en el discurso periódistico y en el tipo de noticias que éste construye: escándolos de corrupción, comentarios de fútbol, modas, juicios no resueltos, dramas humanos. Ahí entran como recurso retórico la narrativización y la personalización de la noticia. La prensa amarilla se mezcla con la rosa y crean un color indefinido, pero jamás abandonando las tonalidades rosáceas.

Lo indicado no es un fenómeno novedoso sí se piensa que ya en 1830 nace el folletín en París, como un espacio interior del periódico destinado a un nuevo público, que es popular, masivo, urbano y semianalfabeto; y bajo nuevos preceptos comunicacionales: ya no se desea informar, sino entretener, comunicar, conmover. De la prensa política se ha pasado a la comercial. La noticia entonces empieza a confundir sus márgenes e introduce en su propio seno la ficción, esa cuota de imaginario reclamada por el diario vivir. La prensa ya no sólo opina o entrega noticias, sino que vende relatos de ficción y hace partícipe a sus lectores de esa producción. A Eugéne Sue, a propósito de su exitoso folletín Los Misterios de París (1842-1843), le llegan miles de cartas para demostrar la injusticia social y empatizar con sus personajes de los bajos fondos y con la posibilidad de su redención, ahí en esos Misterios... nadie es tan malo como aparenta y los marginales son humanizados, redimidos y convertidos en personas. Sue, a partir, de su interacción con el público los hace transitar desde la pasividad de lo exótico a la actividad del sujeto popular. Tanto es la fuerza social que provoca que en 1859 se decreta un impuesto para los periódicos que publiquen folletines, como una manera de coartarlos. De ahí, del folletín, saca el mercado la matriz fundamental de muchos de sus productos: la canción romántica, la telenovela, la prensa amarilla, el best seller. Responder a las demandas de la masa es la consigna de las industrias culturales. Pero esa redención se traslada hoy desde lo social y lo politico a lo simbólico y comercial. El medio se pone al servicio del público, no ya para educarlo, ni manipularlo, sino para entretenerlo, encantarlo, satisfacerlo, merecerlo, acompañarlo en su ocio y descanso, que es cada vez más precario en lo real.

No es casual que en El Salvador los espacios para las telenovelas y los noticieros vayan en horarios correlativos y en el de las más altas audiencias. Y tampoco es casual que en miles de hogares se prefiera mirar la telenovela favorita, en lugar de prestarle atención a los cotidianos problemas económicos, sociales y familiares. 
Además, la confusión no sólo se da en un plano discursivo y cognitivo, sino sobre todo sensorial y emotivo, ya lo decía McLuhan hace varios años: "el medio es el mensaje". La radio y la discografía cambiaron nuestros oidos, la televisión alteró nuestra visión y el ritmo total de nuestras vidas. $\mathrm{Ha}$ aparecido el nuevo sensorium, que tan bien describió Walter Benjamin, se han producido las transformaciones del medium de la percepción, de la experiencia social, una sensibilidad "para lo que en el mundo es del mismo género", una sensibilidad que adapta a la masa una nueva realidad y viceversa (Benjamin 1986). No se trata de promover o aceptar el culto de los medios, sino de pensar la manera en que nos hacemos cargo de los cambios introducidos por estas mediaciones, las que ha tranformado no sólo nuestras comunicaciones, sino la manera total en que participamos socialmente, las modalidades en que aprendemos, nos identificamos, nos socializamos, compartimos o, tenemos miedo o experimentamos el amor.

En tal sentido es que la presente reflexión sugiere prestar atención a esa función social, ese uso colectivo que se hace de las telenovelas, y del cual usufructúan no sólo las grandes transnacionales de las telecomunicaciones y los publicistas, sino también el público. Ese público que empieza a configurarse ya en el siglo XIX, y que irá demandando y reinventando la cultura popular masiva.

\section{V}

No es posible desentenderse del lugar en que la telenovela nace y se desarrolla: el de la televisión. Es impensable desligarse de esta obviedad, ya que ella le impondrá a la telenovela las especificidades discursivas, pero también de circulación (Vilches 1997: 59). En relación a lo primero habría que advertir que la telenovela como en las películas se narra con imágenes no con palabras, por lo que aquí lo discursivo enlaza indisolublemente con lo visual (montaje de escenas), y lo sonoro, no sólo parlamentos, sino música, ruidos, sonidos. Sin embargo, entre los géneros televisivos, la telenovela conserva abundantemente la fuerza del relato, o sea, se presentan historias, pero además los propios personajes narran innumerables situaciones y anécdotas. La trama se desarrolla en paralelo entre lo que se cuenta y lo que se presenta. De alguna forma este género conserva el ritual del relato, en ella se pervive su reminiscencia y su función social. Se niega de pasada el desborde de la imgen y de los recursos fílmicos, "con la telenovela se vuelve a la escasez, al cuento mítico y a la fábula de los arquetipos seculares de la humanidad" (Cornejo Polar 1982: 27). 
En segundo lugar, por su pertenencia a una industria de entretención, la telenovela deberá conmover, seducir, acompañar el cotidiano, porque las historias que se presentan se vinculan con dos grandes preocupaciones vitales de "la persona": sus relaciones amorosas y sus dramas sociales. Una tercera imposición tiene que ver con la obligatoriedad de contar una historia, lo narrativo demandará además privilegiar la escena, el fragmento por sobre la totalidad, y descartar los diálogos por sobre cualquier otro tipo de discurso. Una cuarta exigencia, derivada de ésta, es la necesidad de crear personajes con cuales uno se puede identificar, como consecuencia existe la tendencia enevitable al estereotipo, maniqueo muchas veces, y a la caricatura social, a este proceso de identifcación se le suman el proyección de afectos y el de catarsis. Eso por eso que, por ejemplo, en el proceso de recepción no sea sólo la ingenuidad y la ignorancia las que permiten esa entrega afectiva por parte del espectador, sino que operan pequeñas estrategias y dispositivos psicológicos que permiten la trasposición de la vida personal a la representada por la ficción, de los problemas íntimos a la escena telenovelada.

En relación a su circulación, no es posible pensar ni analizar una telenovela, o culaquier otro producto de la cultura de masas desligándola de sus condiciones de producción y recepción, no sólo por la incidencia de ellas en la elaboración, sino porque su configuración depende de las condiciones económicas, técnicas y productivas de una empresa y no de un sujeto, como ocurre con la obra de arte. Producto cultural, entonces, que va de la empresa al hogar, de las grandes productoras al público masivo y segmentado. En América Latina esas productoras coinciden muchas veces con grandes transmisoras con señal abierta, es el caso de Globo TV en Brasil y de Televisa y Televisión Azteca en México. En El Salvador, opera básicamente una lógica en el mercado de telenovelas, el de las importaciones de éstas ante la ausencia de producciones locales. Para los canales de televisión comerciales esta forma de inversión constituye un negocio muy rentable. Esto se enmarca, desde luego, en la racionalidad del mercado capitalista: el estímulo al consumo y la venta de mercancías (incluyendo diversos productos culturales) con el propósito de obtener ganancias. Por lo que se entiende como la circulación de lo que se programa responde a lógica del beneficio empresarial.

\section{VI}

Un comentario final a manera de conclusión. Todavía resuena en el ambiente una posición descrita hace ya más de treinta años por Um-

\section{1}


berto Eco como apocalítica ante la cultura de masas. Ahí, los medios detentan una demoledora fuerza demoníaca y alienante. Es más, ya la cultura mediática sería inofensiva al lado de la fuerza incontrarrestable de una nueva cultura: la de la sociedad de la información, asociada a la globalización, la informática y al desarrollo de la internet. Sociedad que se inicia con la guerra fría y que terminaría por consumir lo poco que nos queda de identidades nacionales y posiblidad liberadora.

Pero en todo momento de la historia se ha anunciado, desde una trinchera, el fin de algo, del aura, del arte, del humanismo ilustrado, del buen gusto, de la posibilidad de la liberación y desde la otra trinchera, el inicio de una nueva era. "Todo por el vapor y la electricidad", se decía en los albores del ferrocarril, creyendo que esas redes inagurababn "el nuevo vínculo universal”. El correr del tiempo demostró que ninguna técnica o tecnología cambia la cultura por sí misma ni por completo, y que sí lo llega a lograr, lo hace sólo parcialmente y a través de lentos procesos, desiguales y complejos procesos de apropiación, usos y adaptación social.

No se trata entonces de caer rendidos o no frente a fenómenos como el estudiado anteriormente, o de simplemente apagar el televisor y voltearse. Se trata de hacerse cargo de todo aquello que conforma y se enreda en nuestra complicada identidad: híbrida, popular, masiva, mestiza, a ratos histórica y a ratos telenovela.

\section{REFERENCIAS}

Benjamin, W. (1986). Reflections: essays, aphorisms, autobiographical writing. New York: Scocken Books.

Cornejo Polar, A. (1982). Sobre literatura y crítica latinoamericanas. Caracas: Ediciones de la Facultad de Humanidades y Educación, Universidad Central de Venezuela.

García-Canclini, N. (1989). Culturas hibridas: estrategias para entrar y salir de la modernidad. México: Grijalbo.

Gramsci, A. (1971). Selections from the Prison Notebooks, traducido y editado por Hoare, Q. y Nowell-Smith, G., Londres: Lawrence and Wishart.

(1975). Quaderni del carcere. Turin: Valentino Gerratana. 
Jameson, F. (1981). The Political Unconscious: Narrative as a Socially Symbolic Act. Ithaca, NY: Cornell University Press.

Kellner, D. (1989). Critical Theory, Marxism and Modernity. Baltimore: Johns Hopkins University.

Martín-Barbero, J. (1987). De los medios a las mediaciones. Comunicación, cultura y hegemonía. Barcelona: Editorial Gustavo Gilli.

Ricoeur, P. (1984). Time and Narrative 1. Chicago: University of Chicago Press.

Vilches, L. (1997). “La fuerza de los sentimientos”, en Verón, E. y Escudero, L. (comp.). Telenovela. Ficción popular y mutaciones culturales. Barcelona: Editorial Gedisa.

Willimas, R. (1983). Keywords: a vocabulary of culture and society. London: Fontana Paperbacks. 